\title{
A Sliding Mode Controller for Boost Inverter Based Power Management System Using Battery and Photovoltaic System
}

Dipak Kumar Dash ( $\nabla$ dipak.nitrkl@gmail.com )

IIT(ISM) Dhanbad

Pradip Kumar Sadhu

IIT (ISM): Indian Institute of Technology

Alok Kumar Shrivastav

Techno International Batanagar

\section{Research Article}

Keywords: Battery, charging current, HPSO algorithm, SOC, Battery energy storage systems.

Posted Date: April 28th, 2021

DOI: https://doi.org/10.21203/rs.3.rs-241929/v1

License: (c) (i) This work is licensed under a Creative Commons Attribution 4.0 International License.

Read Full License 


\title{
A Sliding Mode Controller for Boost Inverter Based Power Management System Using Battery and Photovoltaic System
}

\author{
Dipak Kumar Dash+, Pradip Kumar Sadhu*, Alok Kumar Shrivastav** \\ ${ }^{+, *}$ Department of Electrical Engineering, Indian Institute of Technology (Indian School of Mines) Dhanbad \\ **Department of Electrical Engineering, Techno International Batanagar \\ \{Corresponding author's email: ${ }^{+}$dipak.nitrkl@gmail.com\}
}

\begin{abstract}
A design tool with appropriate characteristics must be available to support the power management process. A major role of the battery is the Charge State (SOC) or simply the power of the battery measured using the original voltage value. A photovoltaic panel with a $12 \mathrm{~V}$ DC voltage of $650 \mathrm{~W}$ is used in this process. The approach is simulation/modeling which aims to improve battery charging process and controlling the power flow using sliding mode controller to enhance the performance. The goal is to research the energy and power loss of a smart battery-buffered load controller (BBSL) when used for the primary frequency controls on demand (PFC). Firstly, the depletion of battery energy arising from the PFC charging and discharge methods is evaluated. This research analyses the influence of PFC droop properties and dead-bands on the energy loss in a Lithium ion battery, by simulation measurements using a single stage BBSL. The model represents a nonlinear current-dependent resistance to the total voltage decrease of the battery. The energy loss simulated as the energy lost in this resistance is thus measured. HPSO-algorithm used in this analysis is one of the photovoltaic models used in photovoltaic systems, with maximum power, and with optimal conditions. The results showed that the battery charging simulation
\end{abstract}


increased by $0.05 \%$ every 30 minutes. Furthermore, the simulation validation using Matlab/Simulink is carried out with data in accordance with the prototype design, at an efficiency of $88.4 \%$.

Keywords- Battery, charging current, HPSO algorithm, SOC, Battery energy storage systems.

\section{Introduction}

Photovoltaic technology is designed to capture solar energy, the most significant energy source on the earth. However, the largest percentage of the installed photovoltaics is still used as a backup energy source and a smaller percentage as a main source of energy in rural areas. Almost every household that uses a photovoltaic system needs a backup battery. The produced electricity cannot always be used immediately. Therefore the battery will store the energy, and it can be used at night, or when demanded [1]. BESS system is one of the main contributors to empowering this transition and the achievement of demand-side control. Battery energy storage systems (BESS) are suitable not only for grid-scale systems but also for load-side applications under the framework of dynamic demand control (DDC) and demand response control (DRC). Situated at the load side, load-scale BESS can be utilized for a wide range of functions. Primary frequency control (PFC) is one of the services that can be implemented through DDC strategies using load-scale BESS [2-3]. Research related to solar irradiance in tropical climate conditions has been investigated [4]. Sometimes the output voltage of the photovoltaic system is higher than the voltage of the battery. Therefore, it is needed to regulate before starting to charge the battery. Hence, Solar Charge Controller (SCC) can be used to regulate the voltage charging the battery [5]. Application of photovoltaic power sources for interconnection systems for Microgrid systems on the island [6]. Battery capacity is an important characteristic that shows the 
capability of the battery to store electrical energy. The unit of measure is Ampereshours $(\mathrm{Ah})$. Each cell has a voltage of $6 \mathrm{~V}$, and each of them is capable of providing power until the voltage level drops to $3.15 \mathrm{~V}$. Furthermore, if the voltage of each cell is $3.15 \mathrm{~V}$, it will continue to decrease, and its effective capacity will be used [5].

In order to design the photovoltaic system, first, the information about how much power is one area/household needs is required. An excellent way to identify the demanded power is with a simulation on Matlab/Simulink. In this research, a 500W photovoltaic system is being examined in the simulation program. There are few inputs that affect the final production of power, among others: solar irradiance, temperature, panel voltage, panel current, and battery charging process [6]. The MPPT method is a strategy for optimizing the generated power and finding the maximal power point in which the photovoltaic needs to work using the SEPIC converter to increases and decrease the voltage. Moreover, it applies the HPSO, which is based on an observation of a P-V curve and the distinction of power with respect to the voltage. It is shown that the performance of the converter is greatly influenced by the duty cycle. With the MPPT method, the power transferred to the load is maximized. In this example, the highest efficiency is achieved when the load is $52 \mathrm{Ohms}$ or when it is equal to $47.5 \%$ [7].

It is important to comprehend the connection between the variation of the photovoltaic module slope angle and the generation of electrical energy. The purpose of this observation is to find the optimal position of the photovoltaic system to increase the absorption of solar energy when connected to a battery charging system. This prototype will work when the battery voltage levels are in the minimum or maximum state. When the battery voltage is in the minimum state, the charging process will automatically start, and when it has reached the maximum state, the charging process will stop [8]. It 
is crucial to inspect the voltage during the process of charging in order to keep the battery safe for further uses and to preserve its life. Solar Charge Controller (SCC) is adequate for DC voltage and can stabilize the voltage from the photovoltaic that is charging the battery.

A similar study to help maximize the photovoltaic efficiency is using a DyeSensitized Solar Cell (DSSC) device. Additionally, the model parameter was calibrated to prognosticate the maximal efficiency from a DSSC with unknown inductor values. The I-V curve helps to install the photovoltaic system successfully using Trusted Capability Maturity Model (TCMM) with combining resistors in series, with an efficiency of $5.46 \%$ and a tolerance of $<0.1 \%$ [10].

To keep the battery performance in good shape, it is necessary to prevent overcharging. To detect the situation, it is required to have information about the battery capacity. Therefore, battery is equipped with a sensor that functions to check whether the battery is working optimally and to provide information about value of the SOC. The entire control system in battery charging is based on the SOC. In this study, an automatic battery charging device with solar power is analysed. It can charge several batteries based on their voltage level. First, it charges the battery with the lowest voltage level, and it estimates its SOC, then it automatically starts to charge the one with a higher voltage level. The SOC shows the capacity of the battery in percentage, and it is an important parameter for the battery management system. However, SOC cannot be measured directly [11].

The study's purpose is to design an automatic battery charger that uses solar power and to model a photovoltaic system using the HPSO algorithm with a buck-boost converter. The presence of the MPPT in the photovoltaic system is a significant feature that helps to improve the efficiency of the entire power plant. The charging process will 
start when it detects the lowest SOC level. The charging current starts to flow if the SOC of the battery is below than $30 \%$, and it stops when the SOC level is $100 \%$. According to the initial setup of the battery charging system, the sensor will read the lowest SOC value in this case, which is based on the measurements of voltage and current from each battery. It is important to mention again that this battery charging system is modelled using Matlab/Simulink software with MPPT controller and HPSO algorithm. The HPSO algorithm is practically a buck-boost converter circuit whose purpose to optimize battery charging and improving the efficiency of the battery.

\section{Literature Review}

Photovoltaic (PV) devices generate electricity directly from sunlight via an electronic process that occurs naturally in certain types of material, called semiconductors. As long as the semiconductive material is exposed to solar radiation, PV will produce electrical energy. The I-V characteristic of photovoltaic is a typical I-V curve. In order to capture an I-V curve, it is needed to perform the Standard Test Condition (STC) - 1000 Watt per square meter (this number refers to the amount of light energy falling on a given area at a given time) and the temperature of the solar cell needs to be $25^{\circ} \mathrm{C}$. There are three most important points on the I-V curve - Maximum Power Point (MPP), Open Circuit Voltage (Voc), Short Circuit Current (Isc) $[10][12][13][14]$. Alternative energy technologies produce clean energy to meet the world's needs in terms of transportation. Efficiency, storage, and utilization of energy systems play an important role in energy consumption. The level of efficiency for renewable alternative energy technologies provides technical capabilities for experimental and model implementation [7]. The proposed approach to the efficiency of renewable energy sources is calculated computationally [15]. The electric potential of solar photovoltaic and biomass has been implemented in Bangladesh. The efficiency of 
the feasibility of this hybrid energy system to provide sustainable electricity [16]. Application of grid energy storage technology to maximize the absorption of renewable energy. Different optimal strategies for Battery Energy Storage Systems (BESS) coordinate with wind-based generators. Charging and using BESS for network operational constraints are node voltage limits, feeder current limits, and node power balance, etc [18].

\subsection{Maximum Power Point Tracker (MPPT)}

The output values of the photovoltaic systems are nonlinear. The P-V and I-V curves have a peak point that changes along with temperature and irradiance. To achieve high efficiency in the production of electrical energy, the photovoltaics should have a stable output at its maximum point. Photovoltaics do not work automatically at their maximum power, the PV system needs to have MPPT in order to find the point easily and maintain their presence [19]. The quality of the performance of the PV system directly depends on the quality of the MPPT system. If the quality of the performance of the system is needed, the quality of the MPPT system needs to be measured. Therefore the MPPT is an electronic system and it can produce maximum power compared to the mechanical tracking system that changes the position of the module towards the solar position [10][20]. The MPPT technique is based on an iterative method that is on time and complex for comparative techniques. The most commonly used approach is the $\mathrm{P} \& \mathrm{O}$ algorithm. This algorithm is utilized to improve time performance and computational complexity. This technique is flexible for digital signal processing [21]. The maximum power tracking, perturb and observe (PO) algorithm is the simplest algorithm. This research uses a maximum power tracking algorithm with a modification of the $\mathrm{P} \& \mathrm{O}$ algorithms. This condition was tested in steady and dynamic conditions using MATLAB/Simulink. The simulation results 
obtained are compared with $\mathrm{P} \& \mathrm{O}$ algorithms to produce efficiency for maximum power tracking in a fast time [22][23].

HPSO algorithm is one of the Maximum Power Point (MPP) tracking techniques based on incremental measurements of the conductance changes. By comparing the incremental measurements, it can be noticed that the variations in power, voltage, and current are caused by the changes in the temperature and solar irradiance. Figure 1 shows the working concept of the algorithm for finding MPP values in every circumstance. When the value of the conductance is zero then it will maintain at the MPP point. When the value is more than zero, the algorithm will detect the value towards the left, when the value is less than zero, it will detect the value towards the right. Therefore, the system can control the reference voltage in order to maintain power at its maximum point by adjusting the magnitude of the PWM [20][24].

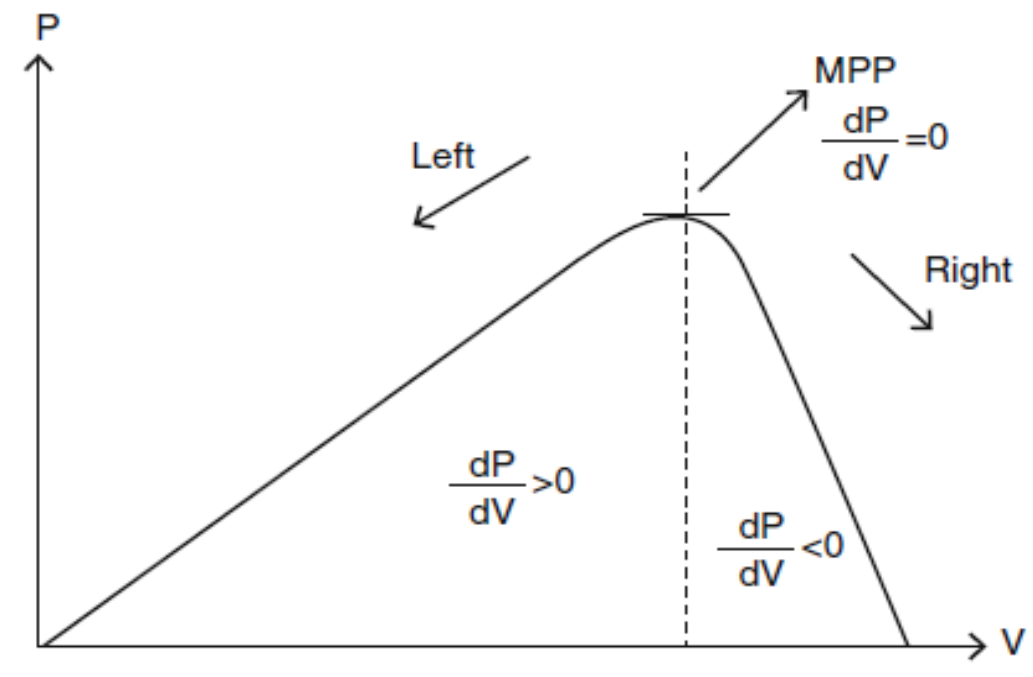

Figure 1. HPSO curve

\section{BBSL AND LOSSES EVALUATION}

The main purpose of the BBSL controller is to control the power consumption of conventional loads according to the operating status of both the grid and the battery. The battery energy storage system will enable the BBSL to autonomously achieve 
different DDC and DRC functions while meeting the load power demands. The contribution of the BBSL to DDC and DRC will depend on the power capability and energy capacity of its associated battery. Here, we focus on the PFC function which is discussed in the following section. Fig.1 shows a diagram of the BBSL. Since the BBSL controller and the battery will result in additional power and energy losses, it will affect the efficiency of the load. For this reason, we investigate the power and energy losses of a BBSL.

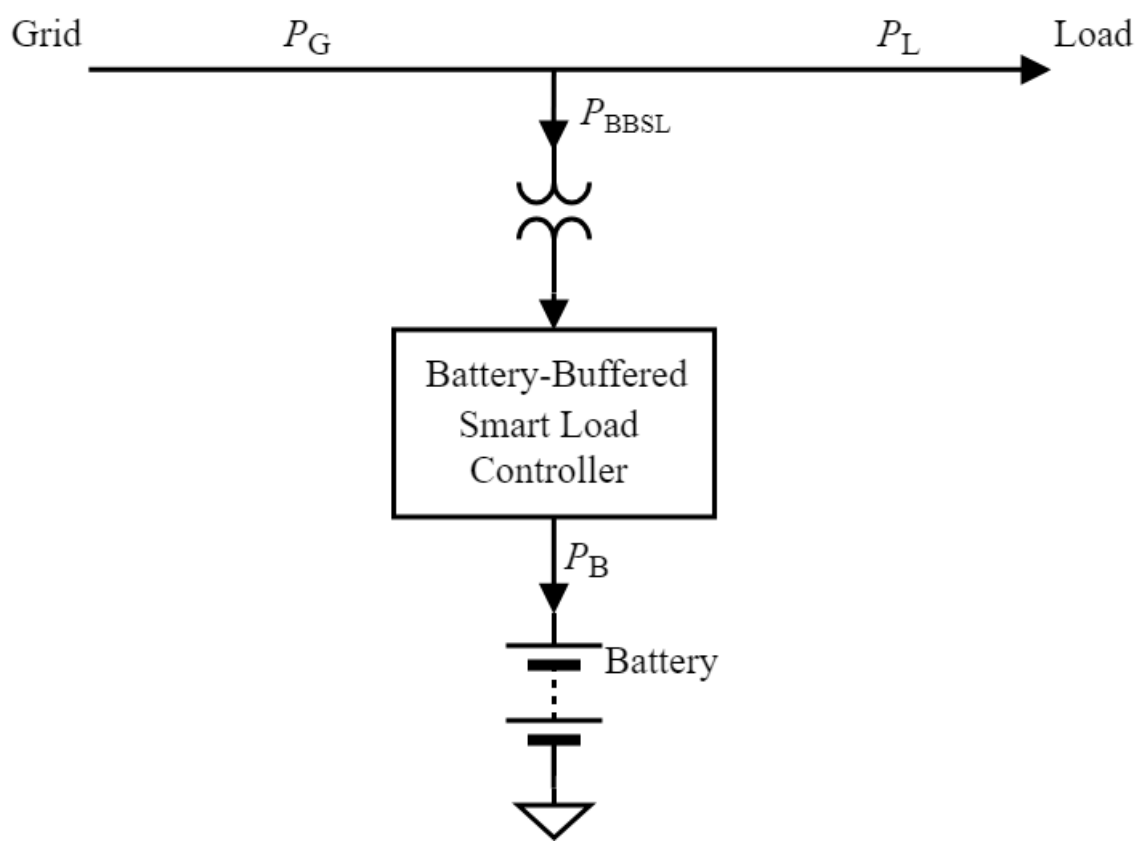

Fig.1. A diagram of the BBSL.

As shown in Fig.1, the grid power flow to the load is given as,

$P_{G}=P_{L}+P_{B B S L}$

where $P_{G}$ is the grid power delivered to both the BBSL, $P_{B B S L}$, and the load, $P_{L} \cdot P_{B B S L}$ covers the battery power $P_{B}$, and power consumed by the BBSL controller $P_{C}$. Therefore, the grid power can be written as,

$P_{G}=P_{L}+P_{B}+P_{C}$

Including control and detecting electronic unit, the inverter and DC/DC converter, the BBSL controller implements the power conversion and control. The total power loss $P_{C}$ 
of the BBSL controller can be divided into an almost-constant part consumed by the control and detecting electronic unit and a part consumed by power electronic circuits. The latter part changes with the power flow processed by the converters. We may assume it proportional to the power flow. Battery storage will result in power and energy losses during charging, discharging and energy storage. The total loss is dependent on the battery type and the way to use the battery. In the following sections, we will mainly discuss the battery energy losses of a BBSL controller working in primary frequency control.

\section{A. Battery Power Control and PFC Function}

In this work, battery power control is designed mainly for the implementation of load-side PFC. At the same time; we also wish to keep the battery SOC around a certain value, for instance, $80 \%$. For this reason, the battery power $P_{B}$ is controlled in two components, line frequency dependent component $P_{B f}(\Delta f)$ and offset component $P_{B S}(S O C)$ for battery SOC compensation as,

$P_{B}=P_{B f}(\Delta f)+P_{B S}(S O C)$

The grid power in (2) becomes,

$P_{G}=P_{L}+\left[P_{B f}(\Delta f)+P_{B S}(S O C)\right]+P_{C}$

It is worth mentioning here that the battery is restricted to discharge its energy only to the associated load and not to feed energy back to the grid. In other words, the BBSL control will meet the condition $P_{G} \geq 0$.

Demand-side PFC is the droop control strategy at load-side. The conventional droop control strategy applied to governors in synchronous generator systems is used to control the BBSL. According to the North American Electric Reliability Corporation (NERC) standards, there are two droop control strategies namely the 
linear response droop and step response droop [25]. The regulation of the battery power is given as follows:

$P_{B f}(\Delta f)= \begin{cases}G_{b} \cdot \Delta f & ;|\Delta f|>\Delta f_{t h} \\ 0 & ;|\Delta f| \leq \Delta f_{t h}\end{cases}$

where $G_{b}$ is the battery power gain in $(\mathrm{W} / \mathrm{Hz})$ calculated as follows

$G_{b}=\frac{1}{R}\left(\frac{p \cdot u \cdot W}{p \cdot u \cdot H z}\right) \times \frac{P_{B, r e f}}{60(H z)}=\frac{1}{R} \times \frac{R_{B, r e f}}{60}(\mathrm{~W} / \mathrm{Hz})$

where $R$ is the droop setting in (p.u. Hz/ p.u. W) and $P_{B, \text { ref }}$ is the reference power of the battery PFC operation. $\Delta f_{t h}$ is the frequency deviation threshold according to the dead-band. $\Delta f=\left(f-f_{o}\right)$ is the frequency deviation and $f_{o}$ is the frequency scheduled value. The offset power $P_{B S}(S O C)$ compensates the battery energy used in the over-frequency and under-frequency regulation and thus preserve the SOC. It is defined based on the SOC deviation as follows:

$P_{B S}=\left(S O C_{\text {set }}-S O C\right) \times B \times P_{b}$

where $S O C_{\text {set }}$ is the set value of SOC. The SOC in this equation is in per unit instead of percent. $P_{b}$ is the battery rated power and $B$ is a gain used to adjust the speed of the offset power compensation to keep the SOC around its set value.

Therefore, the battery power equation can be written as,

$P_{B}(\Delta f, S O C)=\left[P_{B f}(\Delta f)+P_{B S}(S O C)\right]$

$P_{B}(\Delta f, S O C)=\left.G_{b} \cdot \Delta f\right|_{|\Delta f|>\Delta f_{t h}}+\left[\left(S O C_{s e t}-S O C\right) \times B \times P_{b}\right]$

According to the standards of generation units, the capacity headroom for PFC is 10 $\%$ of the rated capacity of the generation unit participating in PFC while the remaining capacity can be managed to meet a targeted demand. The reference capacity for the BBSL system can be ten times the rated power of the battery with the same droop values, $\mathrm{R}$ used in generators, to use the entire capacity of the battery 
for PFC participation and thus have an effect similar to PFC generation. Therefore, the used Lithium ion battery pack that has an appraisal power of $21.6 \mathrm{~W}$ may supply pfc at the power reference $\mathrm{P}(\mathrm{B}, \mathrm{ref})=10$ to $21.6 \mathrm{~W}=216 \mathrm{~W}$. However, the expected power rating of a BBSL should extend from the laptop to a house power supply, i.e. from 100 to $20 \mathrm{kVA}$.

\section{Method}

Optimal determination of the location of Solar Photovoltaics (SPV) and Battery Energy Storage Systems (BESS) in the battery cycle charging system. Optimal management of charging and using the BESS cycle by absorbing SPV as a source of electricity. Significant increase in load deviation index, increase in node voltage profile, reduction in feeder power loss without reverse power flow [3]. Energy management strategy to oversee the flow of power in stand-alone dc microgrid. This power plant consists of photovoltaic and battery storage systems, combined with supercapacitors. Microgrid is modeled using the Matlab/Simulink/SimPowSys environment [8][18][25]. Configuration and control strategies for a Modular Multilevel Converter (MMC) based on Photovoltaic Battery Energy Storage (PV-BES) systems. The BES system for converters is connected to dc from the BES sub-module using several isolated converters. The effectiveness of power leveling techniques using the PV-BES system uses a time-domain simulation in a MATLAB software environment [24].

\subsection{Maximum Power Point Tracker (MPPT)}

In this paper, an automatic battery charger is designed using solar power and a PID is used as a controller. The controller is connected with a $60 \mathrm{Ah}$ battery and a $500 \mathrm{~W}$ PV that has a function to supply the controller if the battery starts to run out. 


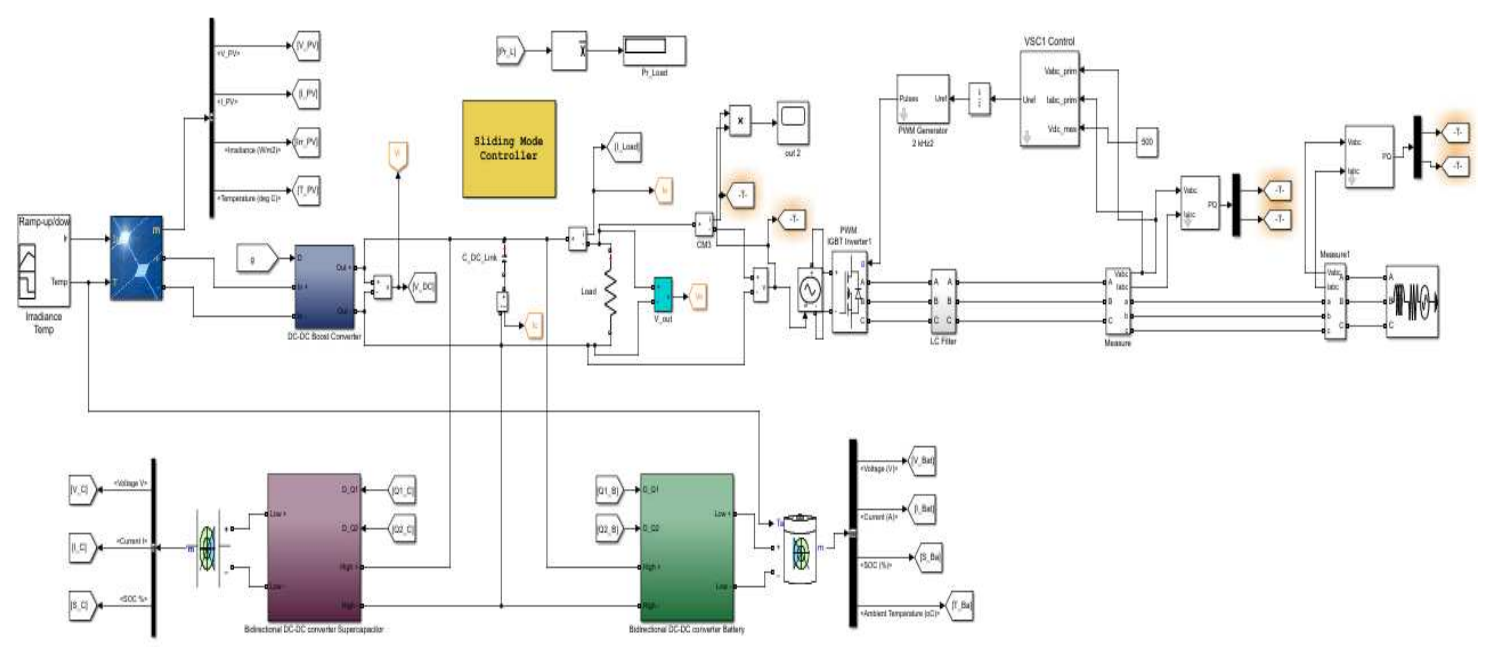

Figure 2. Power Management Using SMC controller

Figure 2 shows an automatic battery charging system combined with photovoltaic sources. This system is almost the same as the conventional charging, but it is far more efficient. Hence the energy generated by the solar cell will be maximized. During the charging, the most important parameters - voltage, current, and SOC values of each battery are displayed on the scope. The nominal battery capacity is marked with $\mathrm{Q}$, and $\mathrm{I}$ is the amount of electric current entering and leaving the battery when the charging process starts. The remaining battery capacity can be calculated by measuring the flow rate of the charging current and integrating with respect to time [11].

\subsection{Modeling of Photovoltaic Battery Charging Systems with sliding mode control} $(S M C)$

The process of modeling a photovoltaic-based battery charging system using the HPSO algorithm is dependable on the design of each component in the PV system such as solar cells, HPSO algorithms, buck-boost converters, and batteries. Each of them is carefully designed in order to fulfill the objectives of the model. In the course of recent decades, sliding mode control (SMC) has become a significant nonlinear control device due to its inherent advantages such as power, perturbations, finite-time convergence, 
insensitivity to parameter variants, and non-linearities. SMC switches device dynamics with an intermediate control input, which allows the system to slip over a selected surface with desired characteristics including stabilization and performance resistance. The state model associated to the dc link of bus and the infinite grid shows the subsequent relations [5]:

$$
\dot{X}=h(x)+z(x) \cdot u
$$

Where, $X=\left(x_{1}, x_{2}, x_{3}\right)^{T}=\left(i_{d}, i_{q}, v_{d c}\right)^{T}$ is the state vector, $u=\left(u_{1}, u_{2}\right)^{T}=\left(v_{d}, v_{q}\right)^{T}$ is the input vector and the state model of the system can be expressed as:

$$
h(x)=\left(\begin{array}{l}
h_{1}(x) \\
h_{2}(x) \\
h_{3}(x)
\end{array}\right)=\left(\begin{array}{l}
-\frac{R}{L} \cdot h_{1}+\omega \cdot h_{2}-\frac{e_{d}}{L} \\
-\frac{R}{L} \cdot h_{2}+\omega \cdot h_{1}-\frac{e_{q}}{L} \\
\frac{i_{p v}}{C}-\frac{e_{d} \cdot x_{1}+e_{q} \cdot x_{2}}{C \cdot x_{3}}
\end{array}\right), z(x)=\left(\begin{array}{cc}
\frac{1}{L} & 0 \\
0 & \frac{1}{L} \\
0 & 0
\end{array}\right)
$$

The state model of a nonlinear (11) is given for the grid-connected PV inverter, the SMC is ideal for this system. The goal is to control the voltage of the output terminal $x_{3}$ (i.e. $v_{d c}$ ) at the full output of the PV array source by means of the built controller. The power factor of a required value can also be achieved by intervention on the status $x_{2}$ ( $i_{q}$ part of current flowing via grid) (to regulate the reactive power delivered to the grid). Therefore, the model outputs of such two conditions expressed as: $y=\left(y_{1}, y_{2}\right)^{T}=\left(x_{1}, x_{3}\right)^{T}=\left(i_{d}, v_{d c}\right)^{T}$. The similar orders of $y_{1}$ and $y_{2}$ are $d_{1}=1$ and $d_{2}=2$ approximately. Therefore, the state model specified by equation (11) can be expressed as:

$$
\left(\begin{array}{l}
\dot{y_{1}} \\
\ddot{y_{2}}
\end{array}\right)=M(x)+N(x)\left(\begin{array}{l}
u_{1} \\
u_{2}
\end{array}\right)
$$


Where;

$$
\begin{aligned}
& M(x)=\left(\frac{i_{p v}}{C}-\frac{1}{C \cdot x_{3}}\left(e_{d} \cdot f_{1}+e_{q} \cdot f_{2}\right)+\frac{\left(e_{d} \cdot x_{1}+e_{q} \cdot x_{2}\right)}{C \cdot x_{3}^{2}} \cdot f_{3}\right) \\
& N(x)=\left(\begin{array}{cc}
0 & \frac{1}{L} \\
-\frac{e_{d}}{L C x_{3}} & \frac{e_{q}}{L C x_{3}}
\end{array}\right) \text { is a non-singular decoupling matrix. }
\end{aligned}
$$

The control scheme can be expressed as:

$$
\left(\begin{array}{l}
u_{1} \\
u_{2}
\end{array}\right)=M^{i}(x) \cdot\left[\left(\begin{array}{c}
i_{q r e f} \\
. . \\
V_{d c r e f}+\lambda e_{2}
\end{array}\right)-N(x)+K_{0} \cdot S_{l}+K \cdot S_{g n}\left(S_{l}\right)\right]
$$

Where: $S_{l}=\left(\begin{array}{l}S_{l 1} \\ S_{l 2}\end{array}\right)=\left(\begin{array}{c}e_{1} \\ \dot{e_{2}}+\lambda e_{2}\end{array}\right)$

\section{Results and Discussion}

The automatic battery charger in its design has several logic components such as PIDs, PWM generator, First order filter etc. This controller logic is used as a battery charging controller and it will be connected to the PV system. The test duration was 2 minutes with an average weather temperature of $30^{\circ} \mathrm{C}$, and an average solar panel temperature of $38^{\circ} \mathrm{C}$. The test was done with voltage values of the batteries - battery 1 of $11.59 \mathrm{~V}$ with a SOC value of $41.86 \%$ and battery 2 of $11.95 \mathrm{~V}$ with a SOC value of 98.91\%. Figure 4 (a) shows the battery voltage deviation during the charging process. 


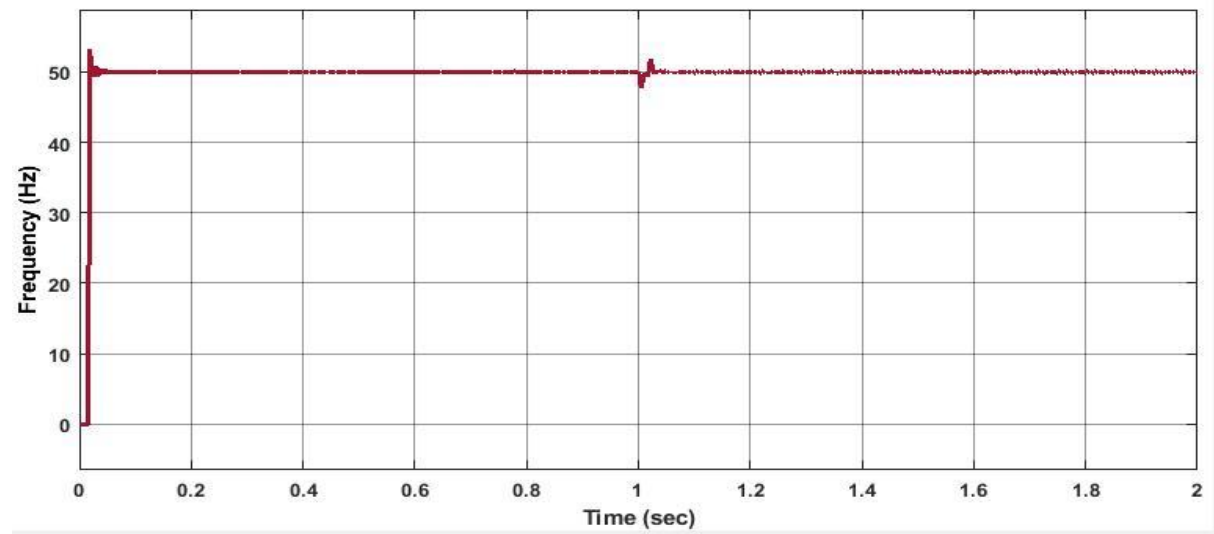

(a)

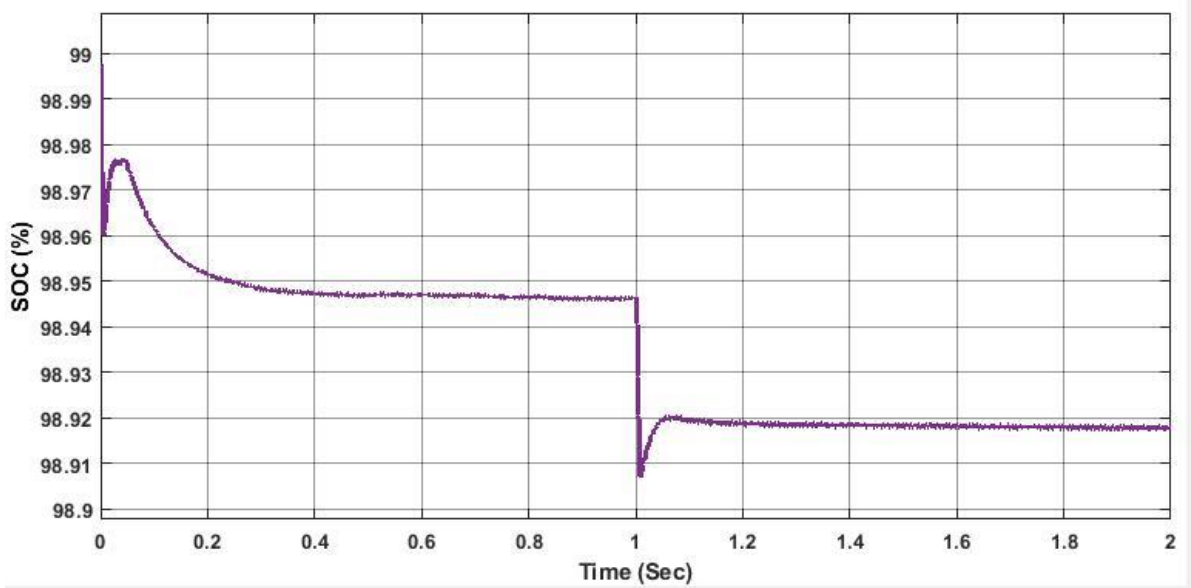

(b)

Fig.4. Practical frequency deviation and simulated SOC for one-day PFC simulation.

To study the effect of the droop settings and dead-bands on energy loss, different experimental tests were conducted with the $21.6 \mathrm{~W}$ Lithium ion battery. Figure 5 shows the flow of the current through the battery while the process of charging is active. The charging current in the battery has a maximum value of $4.99 \mathrm{~A}$.

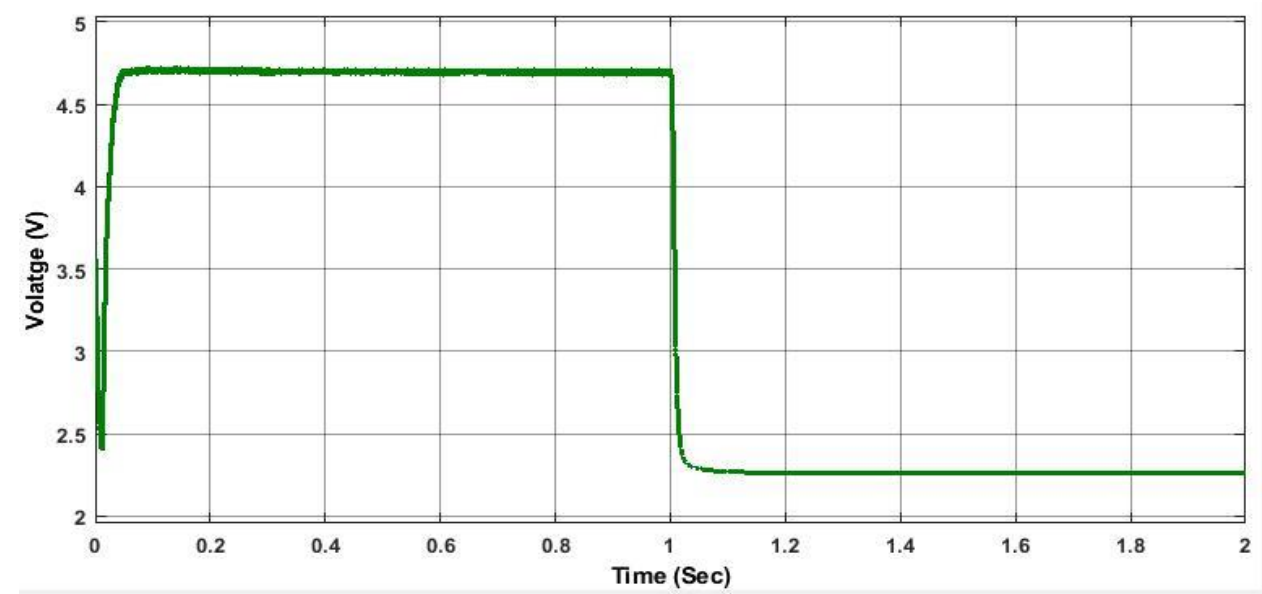

(a) frequency deviation 


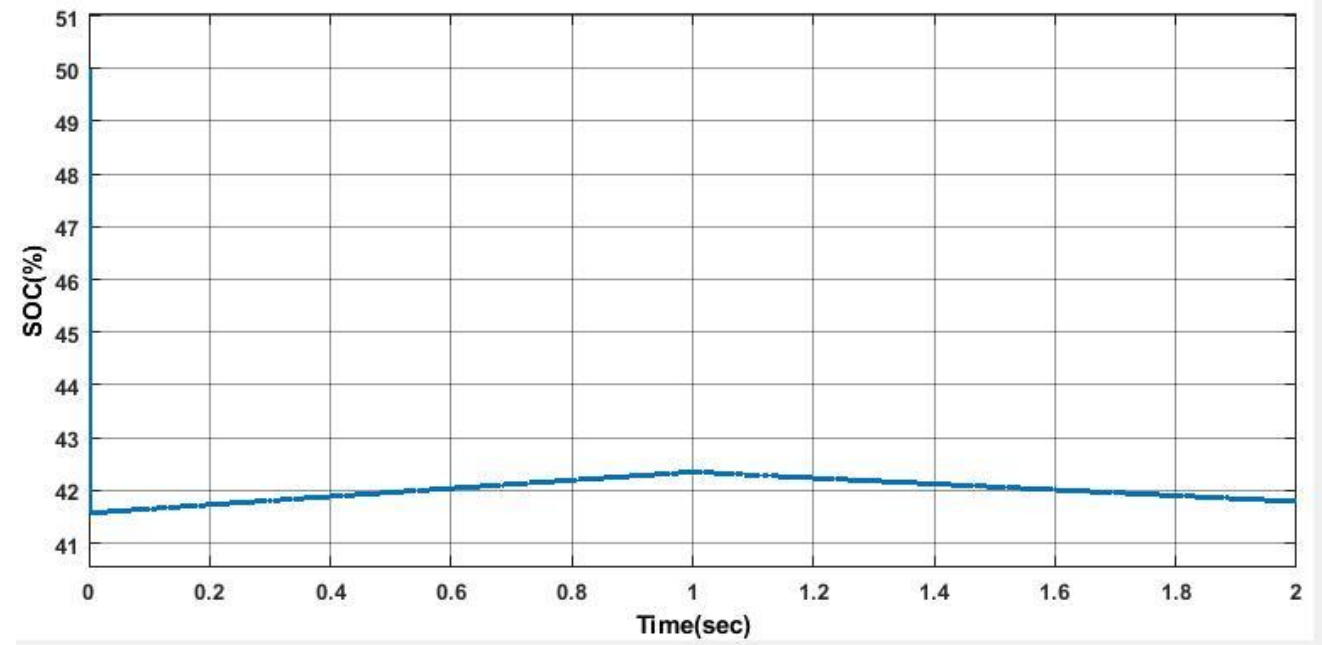

(b) $\%$ of SOC

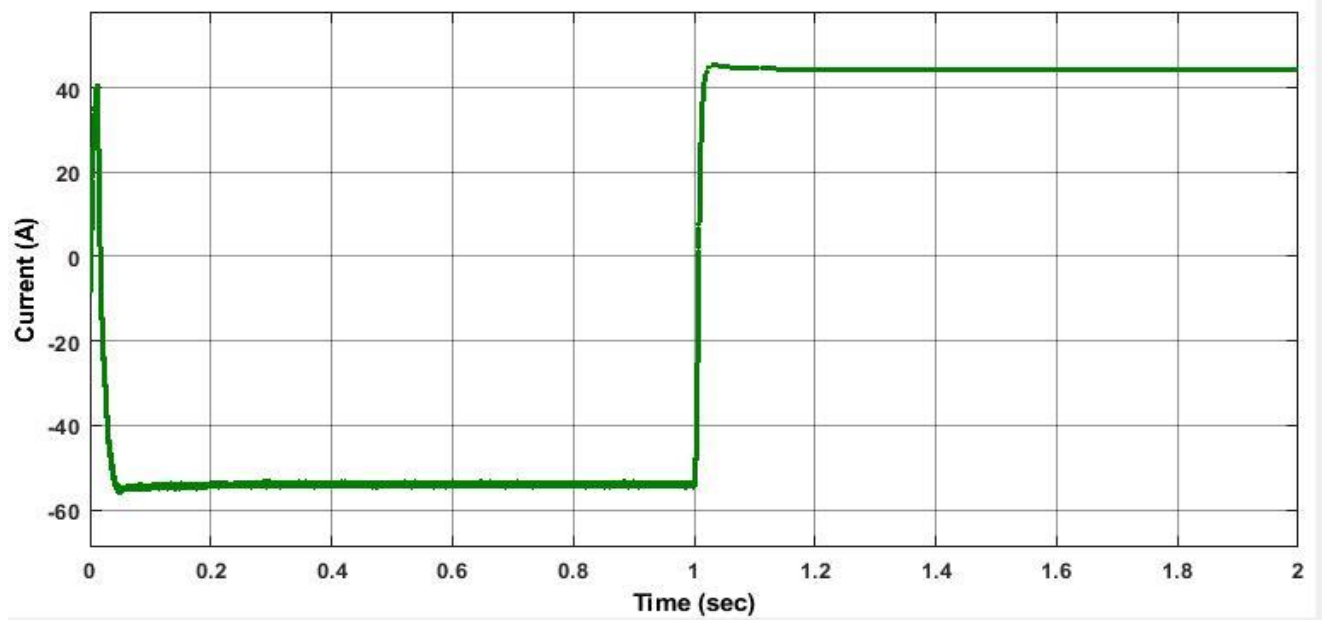

(c) Battery Current

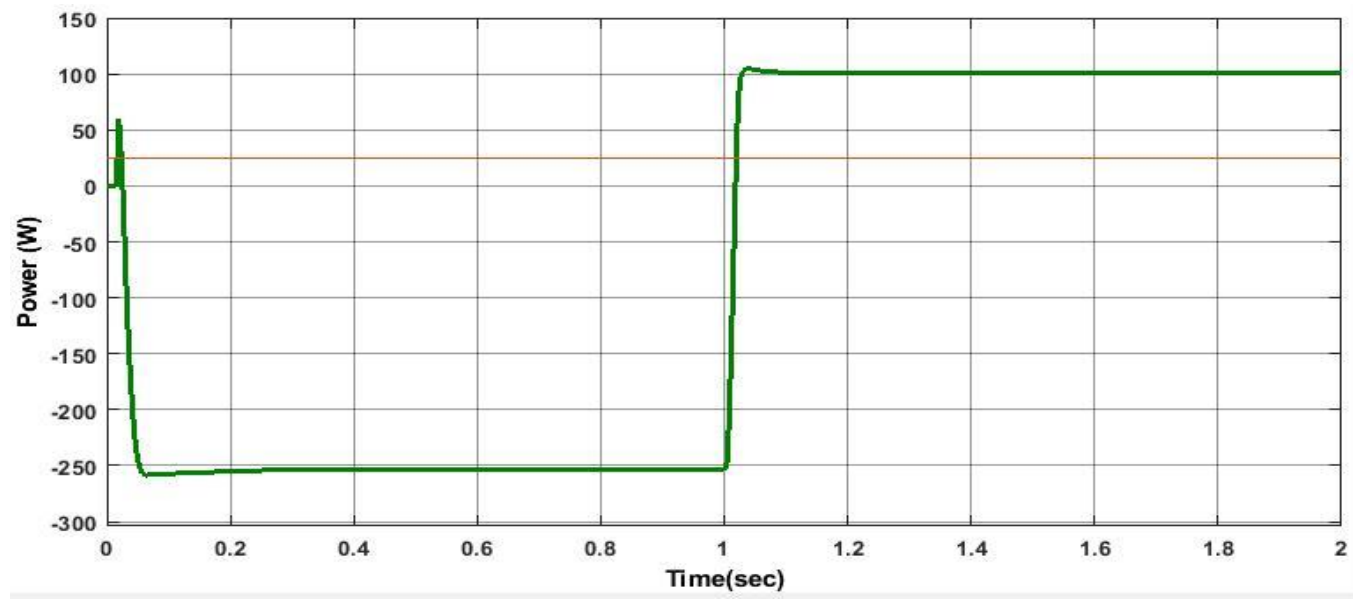

(d) Battery Power

Fig.5. Simulation results of frequency deviation, SOC, battery current and battery power.

Figure 6 shows the increasing of the SOC value of batteries. The SOC value of battery 1 increases from $41.86 \%$ to $50.6 \%$. 


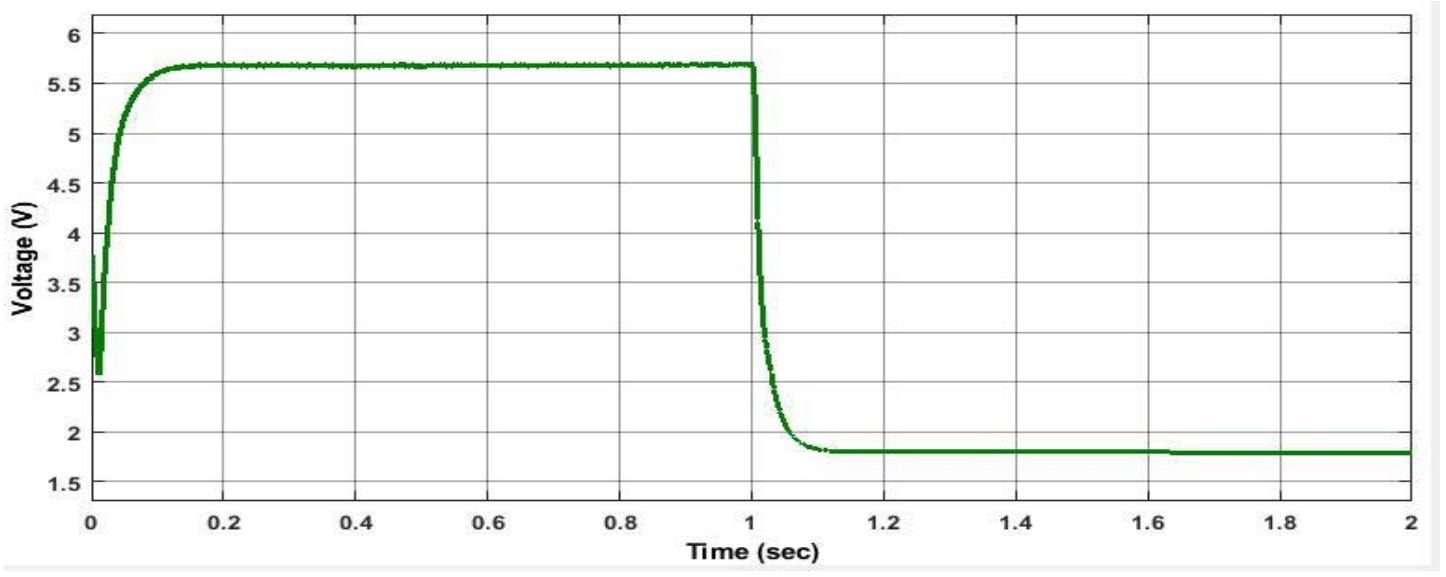

(a) Frequency Deviation

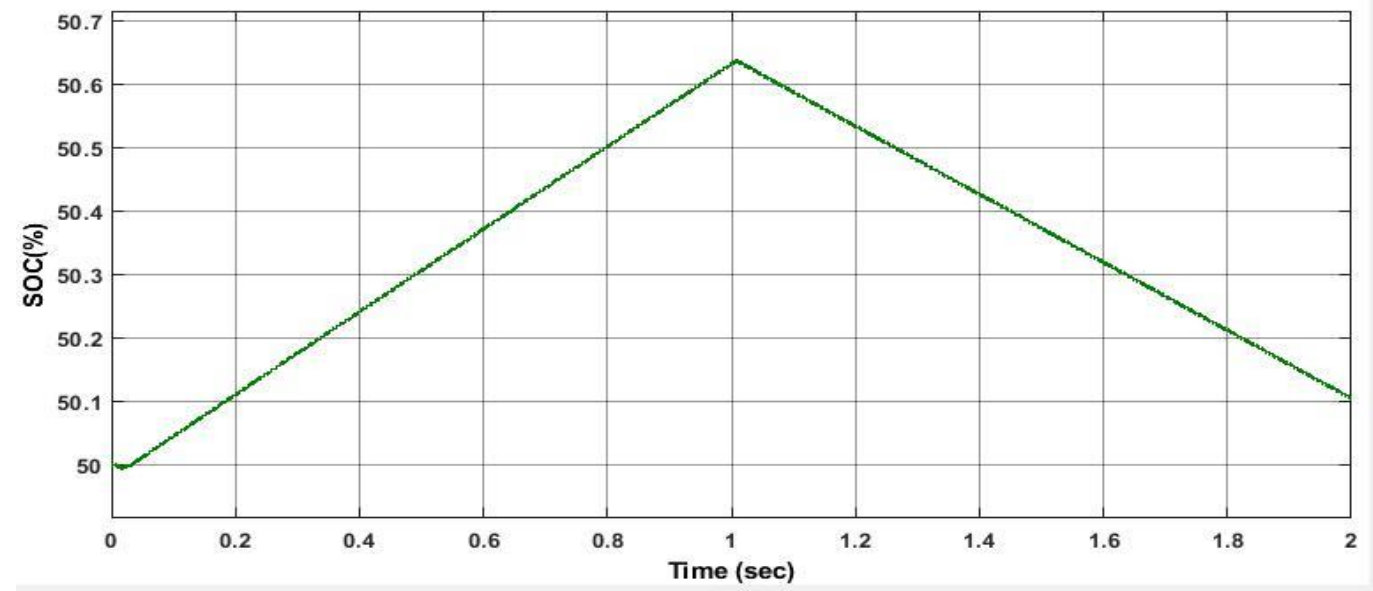

(b) $\%$ of SOC

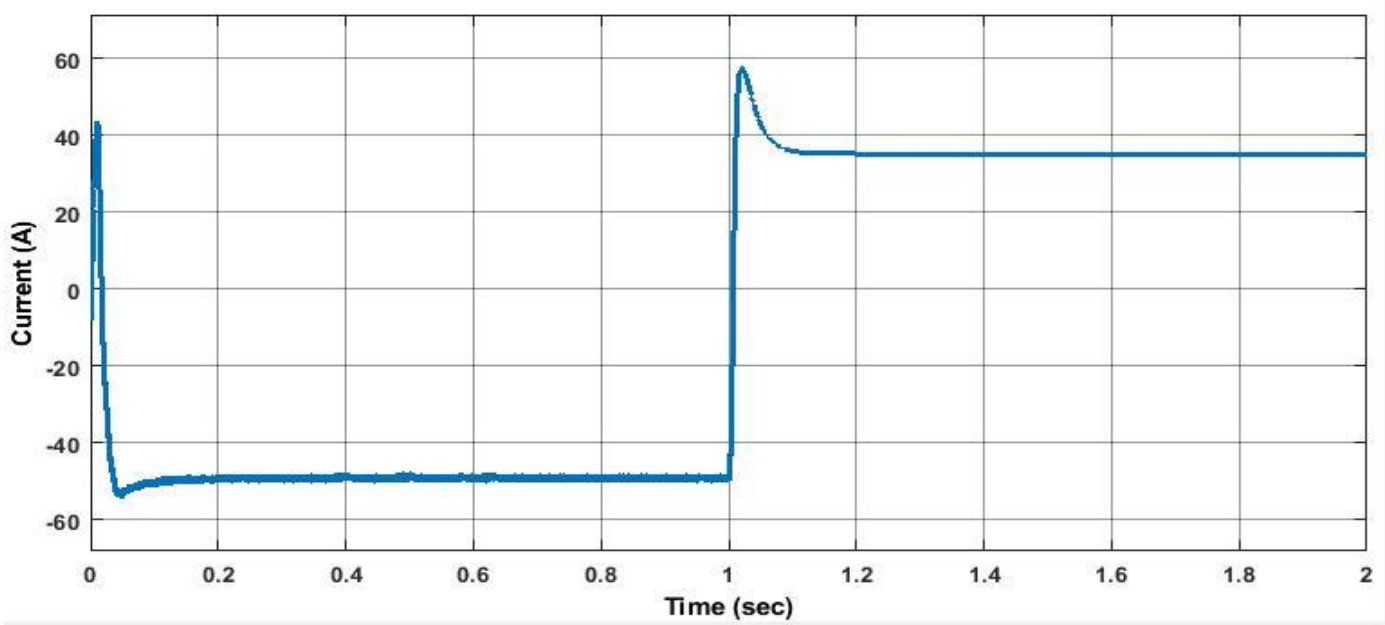

(c) Battery Current 


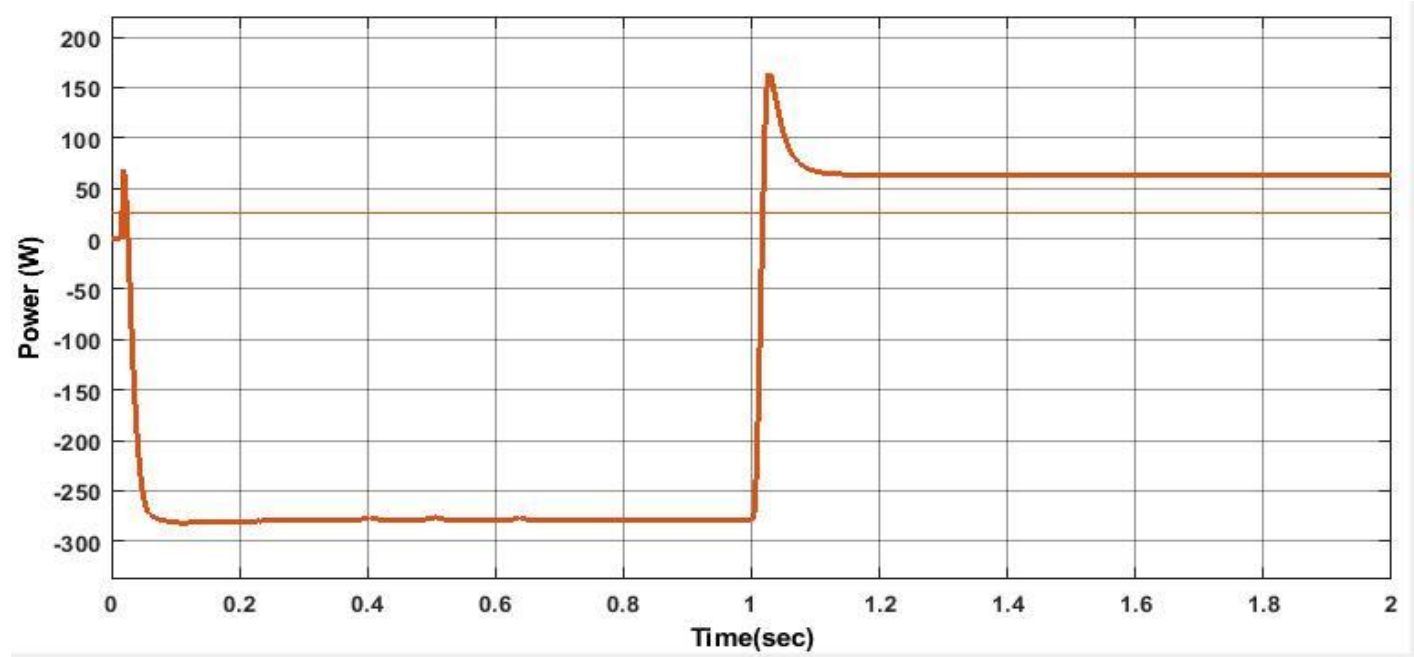

(d) Battery Power

Fig. 6 Experimental results of frequency deviation, SOC, battery current, and battery power

Figure 6 (a) shows a simulation that recorded an increase in the battery SOC value of $0.05 \%$ (from $50.01 \%$ to $50.06 \%$ ) for a simulation test time of 2 seconds, and spent 30 minutes. Figure 6 (b) shows the charging current that flows through the battery during the charging process. The charging current increases to a value close to $45 \mathrm{~A}$, it starts to decrease, and it approaches the value of 40A. The variation is different from the charging voltage shown in Figure 6 (c). Figure 6 (d) shows the variation in battery power. As for the increasing in SOC, it can't be seen significantly because of the length of the Simulink battery charging simulation process. Based on the design, test, and simulation, the final efficiency is $82.37 \%$ calculated with solar irradiation of $1000 \mathrm{~W} / \mathrm{m} 2$ and temperature of the solar cells of $25^{\circ} \mathrm{C}$ in the MATLAB/Simulink environment.

Figure 7 is the irradiation condition of solar cells with different efficiency values. The change in output power is low, the solar irradiation gets smaller. Therefore, the efficiency value is calculated while simultaneously comparing the maximum power and ideal solar cell power during the simulation. 


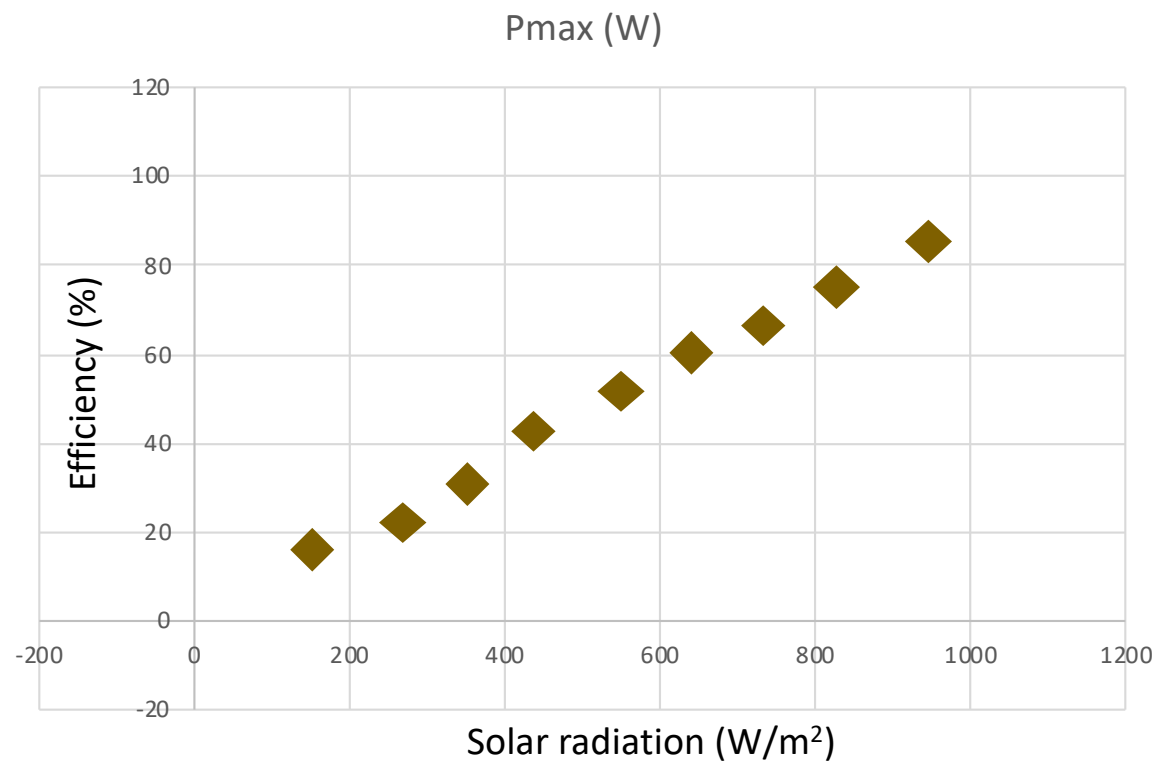

Figure 7. The efficiency and maximum power

\section{Conclusion}

A battery-buffered smart load is used for primary frequency control of the load side to check energy loss of Lithium ion batteries. The loss in battery energy therefore depends heavily on the time of death and drop. Also, simulation results showed that lowering the droop constant increases energy loss as the regulation charge-discharge current is increased. The results can provide valuable insights into the design of load-side PFC to compromise the benefits of the battery to the frequency control and the energy lost in the battery in the PFC load-discharge energy exchange, on the one hand, and the power lost by the converters. If the charging process is done with implementing the standard test conditions, the increase of the SOC value in each iteration is greater compared to the value obtained in Matlab/Simulink simulation. Based on the results of the simulation made in Matlab/Simulink concerning the prototype design and using the MPPT HPSO algorithm, the calculated final efficiency is $88.4 \%$. 


\section{Compliance with Ethical Standards}

1. Disclosure of potential conflicts of interest: The authors declare that they have no conflict of interest.

2. Research involving human participants and/or animals: This paper does not contain any studies with human participants or animals performed by any of the authors.

3. Informed consent: Informed consent was obtained from all individual participants included in the study

4. Funding: This study was not funded by any agencies.

\section{Authorship contributions}

1. All authors made substantial contributions to the conception or design of the work; or the acquisition, analysis, or interpretation of data; or the creation of new software used in the work;

2. All authors drafted the work or revised it critically for important intellectual content;

3. All authors approved the version to be published; and

4. All authors agree to be accountable for all aspects of the work in ensuring that questions related to the accuracy or integrity of any part of the work are appropriately investigated and resolved. 


\section{References}

[1] Nikolay Lyuboslavov Hinov, Rad Hristov Stanev and Gergana Ilieva Vacheva, "A Power Electronic Smart Load Controller for Nanogrids and Autonomous Power Systems", Proc. XXV International Scientific Conference Electronics - ET2016, 2016.

[2] S. Rauf, S. Rasool, M. Rizwan, M. Yousaf and N. Khan, "Domestic electrical load management using smart grid", Energy Procedia, vol. 100, pp. 253-260, 2016.

[3] Johanna L. Mathieu, "State Estimation and Control of Electric Loads to Manage Real-Time Energy Imbalance", IEEE Transactions on Power Systems, vol. 28, no. 1, pp. 430-440, 2013.

[4] J. M. E. Huerta, J. Castelló-Moreno, J. R. Fischer, and R. García-Gil, "A Synchronous Reference Frame Robust Predictive Current Control for Three-Phase Grid-Connected Inverters," IEEE Trans. on Ind. Electron., vol. 57, No. 3, pp. 954-962, March 2010.

[5] Kasis, E. Devane, C. Spanias and I. Lestas, "Primary Frequency Regulation with Load-Side Participation Part I: Stability and Optimality", IEEE Transactions on Power Systems, vol. 32, no. 5, pp. 3505-3518, Sept. 2017.

[6] Kasis, E. Devane, C. Spanias and I. Lestas, "Primary Frequency Regulation with Load-Side Participation Part II: Beyond Passivity Approaches", IEEE Transactions on Power Systems, vol. 32, no. 5, pp. 3519-3528, Sept. 2017.

[7] Geertje Schuitema, Lisa Ryan and Claudia Aravena, "The Consumer's Role in Flexible Energy Systems: An Interdisciplinary Approach to Changing Consumers' Behavior", IEEE Power and Energy Magazine, vol. 15, no. 1, pp. 53-60, 2017.

[8] Jonathan Brooks, Prabir Barooah, "Coordination of Loads for Ancillary Services With Fourier Domain Consumer QoS Constraints", Smart Grid IEEE Transactions on, vol. 10, no. 6, pp. 6148-6155, 2019.

[9] Y.-J. Kim, E. Fuentes and L. K. Norford, "Experimental study of grid frequency regulation ancillary service of a variable speed heat pump", IEEE Trans. Power Syst., vol. 31, no. 4, pp. 3090-3099, Jul. 2016.

[10] K. O. Aduda, T. Labeodan and W. Zeiler, "Towards critical performance considerations for using office buildings as a power flexibility resource-a survey", Energy Build., vol. 159, pp. 164-178, Jan. 2018.

[11] Y. Lin, P. Barooah, S. Meyn and T. Middelkoop, "Experimental evaluation of frequency regulation from commercial building HVAC systems", IEEE Trans. Smart Grid, vol. 6, no. 2, pp. 776-783, Mar. 2015.

[12] Y. Chen, M. U. Hashmi, J. Mathias, A. Bušić and S. Meyn, "Distributed control design for balancing the grid using flexible loads" in IMA Volume on the Control of Energy Markets and Grids, New York, NY, USA: Springer, pp. 1-26, 2017.

[13] E. Vrettos, F. Oldewurtel and G. Andersson, "Robust energy-constrained frequency reserves from aggregations of commercial buildings", IEEE Trans. Power Syst., vol. 31, no. 6, pp. 4272-4285, Nov. 2016. 
[14] E. Mallada, C. Zhao and S. Low, "Optimal load-side control for frequency regulation in smart grids", IEEE Trans. Autom. Control, vol. 62, no. 12, pp. 6294-6309, Dec. 2017.

[15] J. S. Vardakas, N. Zorba and C. V. Verikoukis, "A survey on demand response programs in smart grids: Pricing methods and optimization algorithms", IEEE Commun. Surveys Tuts., vol. 17, no. 1, pp. 152-178, 1st Quart. 2015.

[16] H. B. da Silva and L. P. Santiago, "On the trade-off between real-time pricing and the social acceptability costs of demand response", Renew. Sustain. Energy Rev., vol. 81, no. 1, pp. 1513-1521, 2018.

[17] C. Zhao, U. Topcu, N. Li and S. Low, "Design and stability of load-side primary frequency control in power systems", IEEE Trans. Autom. Control, vol. 59, no. 5, pp. 1177-1189, May 2014.

[18] J. Brooks and P. Barooah, "Consumer-aware distributed demand-side contingency service in the power grid", IEEE Trans. Control Netw. Syst., vol. 5, no. 4, pp. 1987-1997, Dec. 2018.

[19] M. Alizadeh, T.-H. Chang and A. Scaglione, "Grid integration of distributed renewables through coordinated demand response", Proc. IEEE 51st Annu. Conf. Decis. Control (CDC), pp. 3666-3671, 2012.

[20] P. J. Douglass, R. Garcia-Valle, P. Nyeng, J. Østergaard and M. Togeby, "Demand as frequency controlled reserve: Implementation and practical demonstration", Proc. 2nd IEEE PES Int. Conf. Exhibit. Innov. Smart Grid Technol., pp. 1-7, Dec 2011.

[21] C.-T. Pan and T.-Y. Chang, "An Improved Hysteresis Current Controller for Reducing Switching Frequency," IEEE Trans. on Power Electronics, vol. 9 No.1, pp. 97-104, 1994.

[22] P. Barooah, "Virtual energy storage from flexible loads: Distributed control with QoS constraints" in Smart Grid Control, Cham, Switzerland:Springer, pp. 99-115, 2019.

[23] J. Kang, F. Yan, P. Zhang, and C. Du, "A novel way to calculate energy efficiency for rechargeable batteries," J. Power Sources, vol. 206, pp. 310-314, 2012.

[24] R. Lu, A. Yang, Y. Xue, L. Xu, and C. Zhu, "Analysis of the key factors affecting the energy efficiency of batteries in electric vehicle," World Electr. Veh. J., vol. 4, no. 2, pp. 9-13, 2010.

[25] C. Zhao, H. Yin, Z. Yang, and C. Ma, "A quantitative comparative study of efficiency for battery-ultracapacitor hybrid systems," in Proceedings, 2014 - 40th Annual Conference of the IEEE Industrial Electronics Society, 2014, pp. 3076-3082.

[26] H. Ohmori, H. Iwai, K. Itakura, M. Saito, and H. Yoshida, "Numerical prediction of system round-trip efficiency and feasible operating conditions of small-scale solid oxide iron-air battery," J. Power Sources, vol. 309, pp. 160-168, 2016.

[27] J. Fleer and P. Stenzel, "Impact analysis of different operation strategies for battery energy storage systems providing primary control reserve," J. Energy Storage, vol. 8, pp. 320-338, 2016. 
Figures

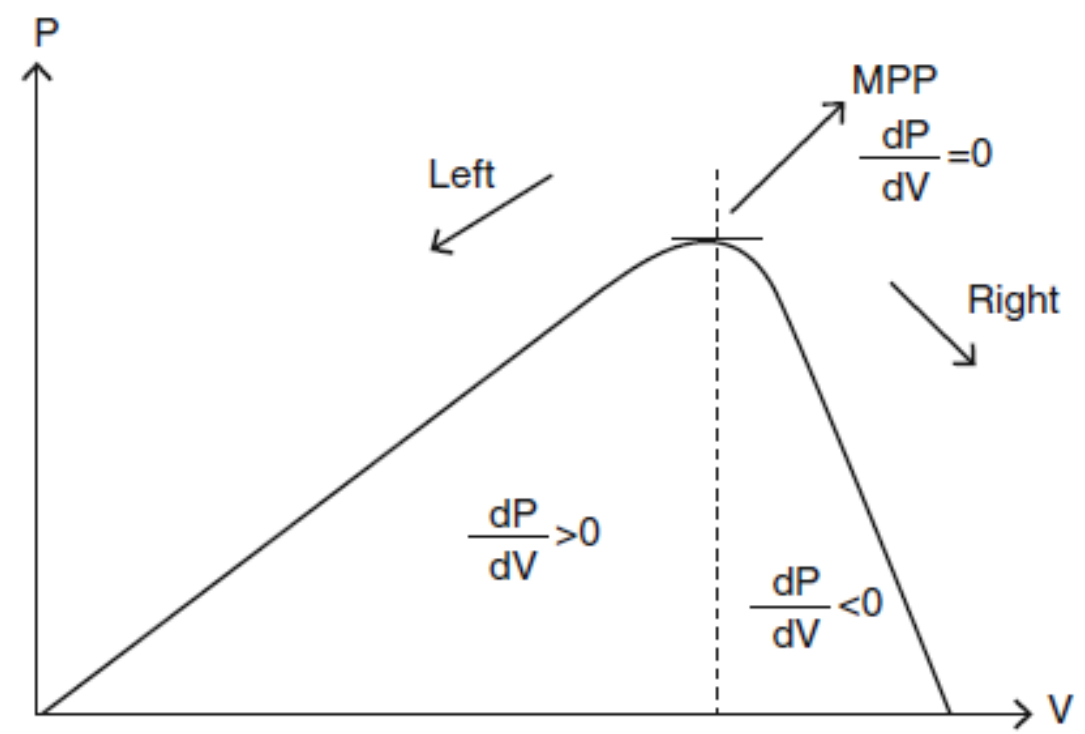

Figure 1

HPSO curve

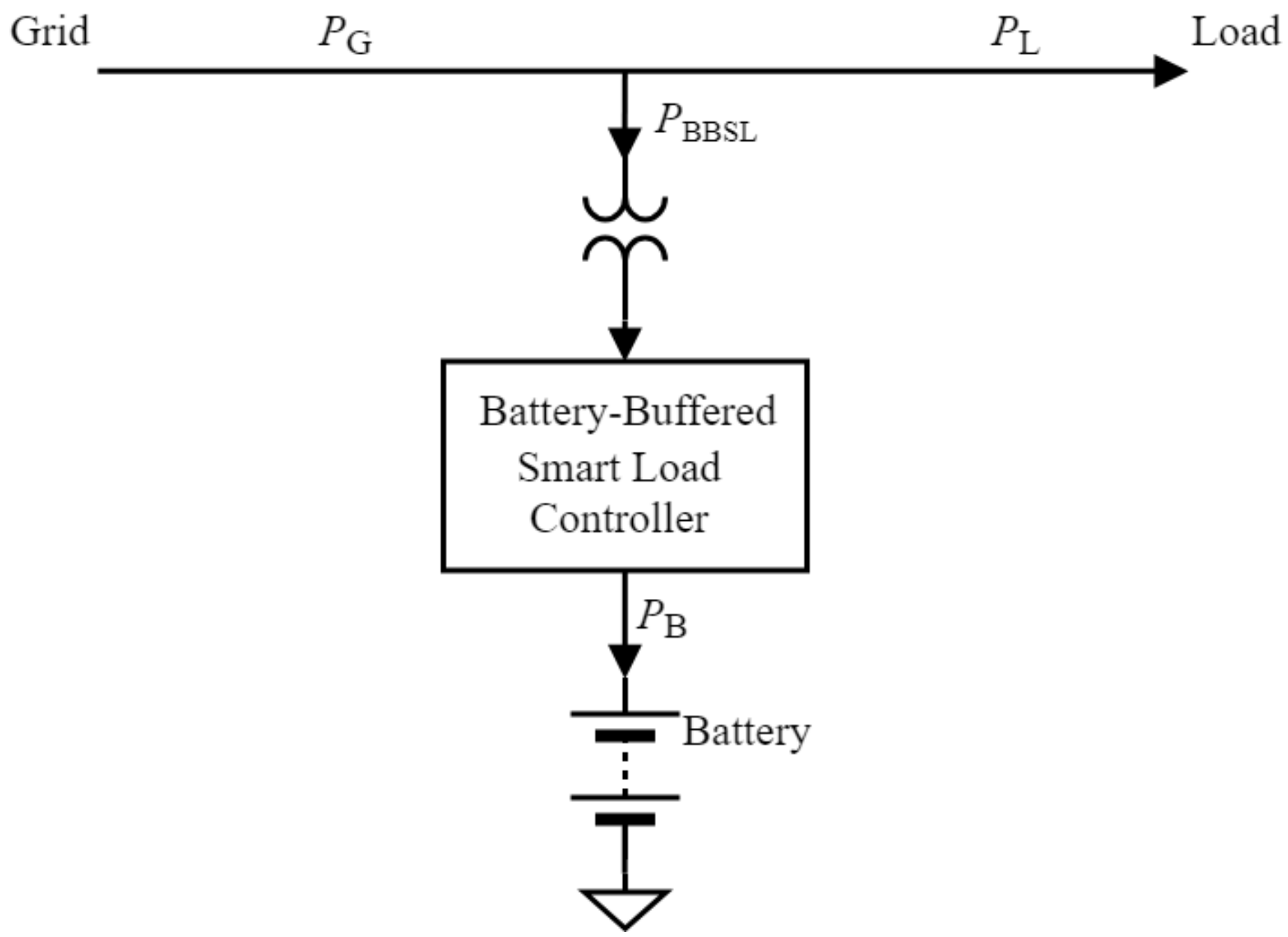


Figure 2

A diagram of the BBSL.

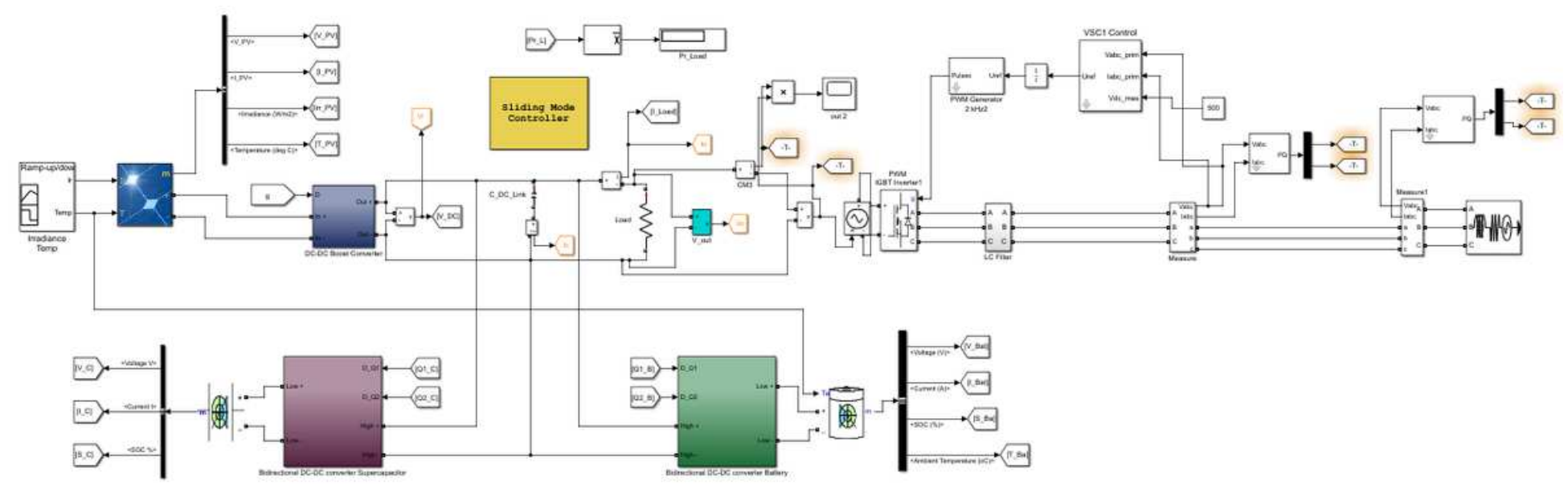

Figure 3

Power Management Using SMC controller 


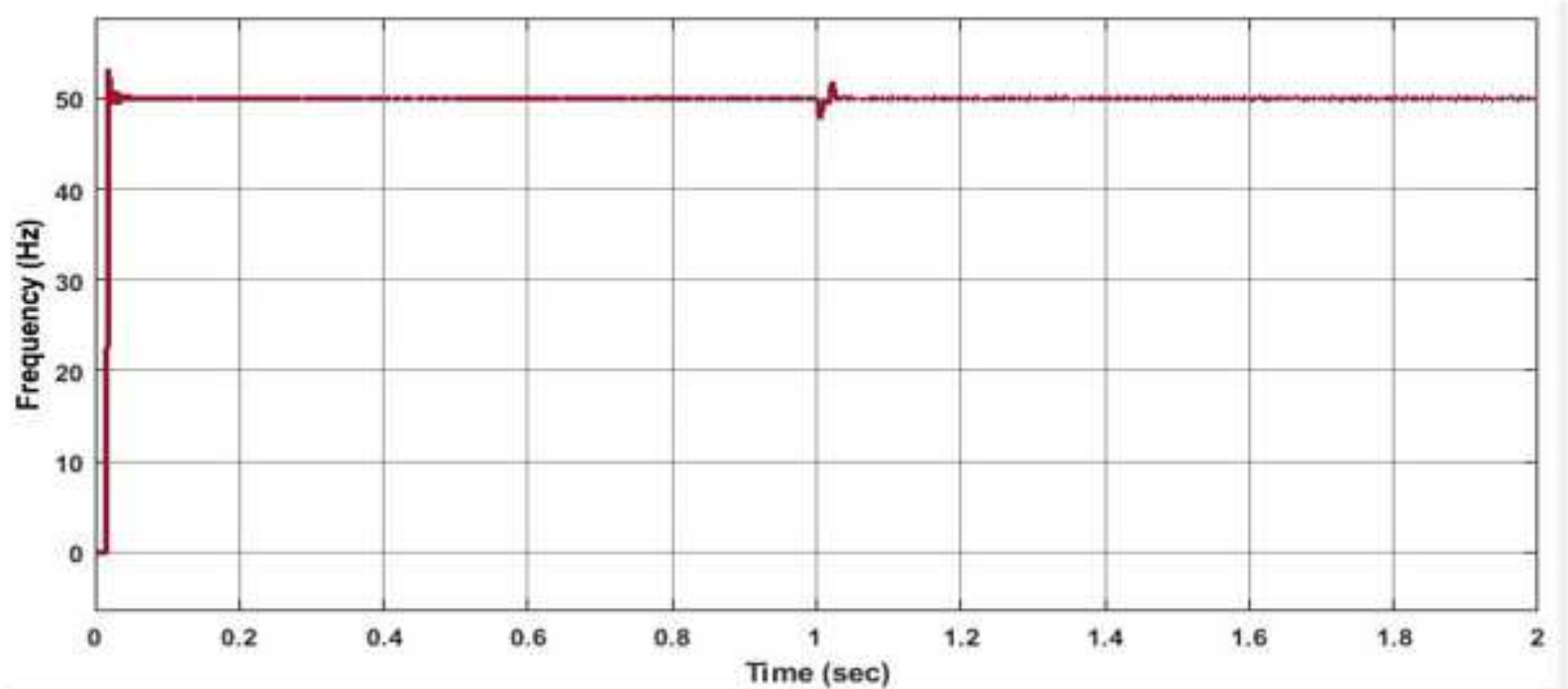

(a)

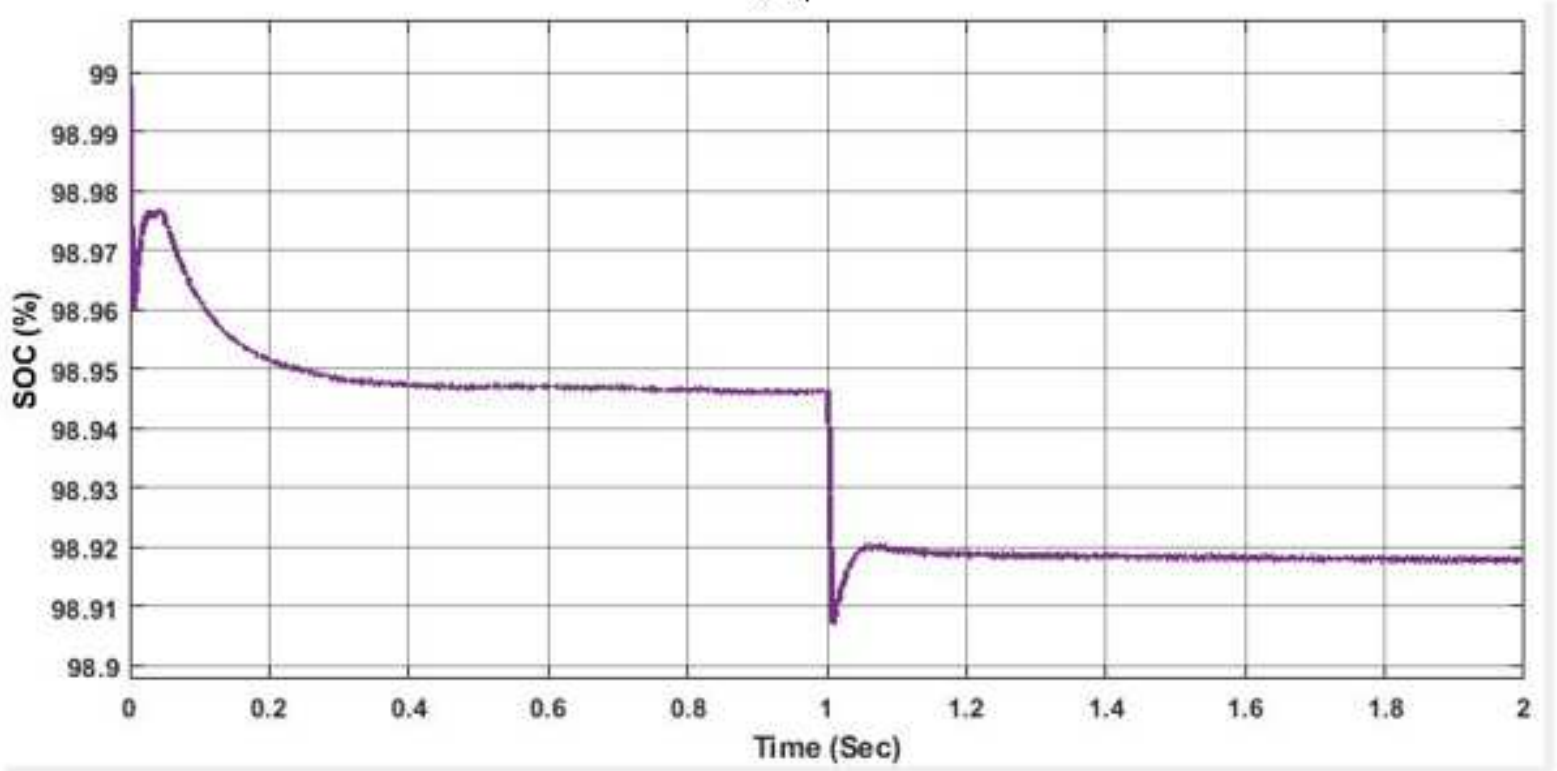

(b)

Figure 4

Practical frequency deviation and simulated SOC for one-day PFC simulation. 


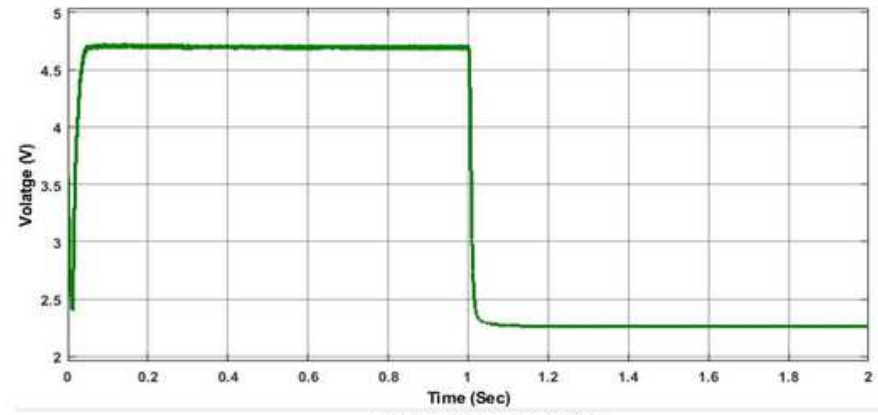

(a) frequency deviation

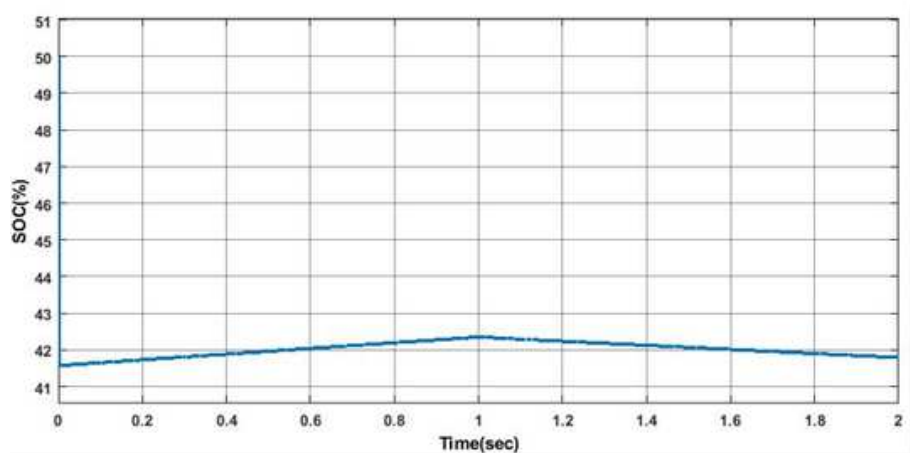

(b) $\%$ of SOC

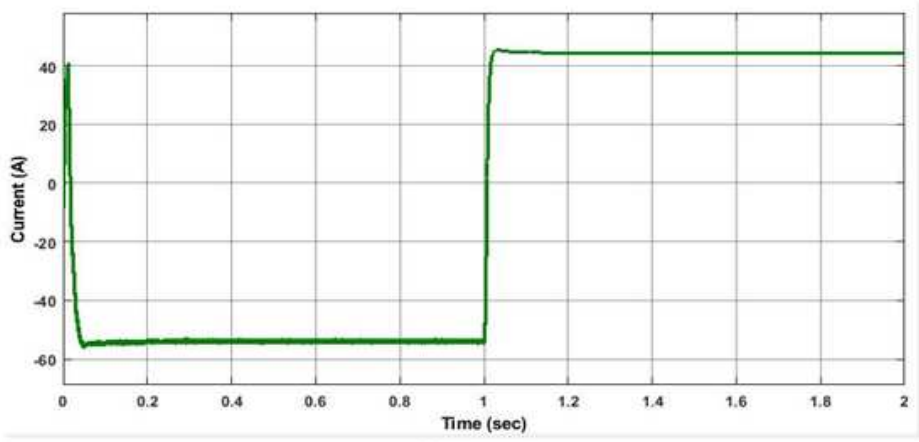

(c) Battery Current

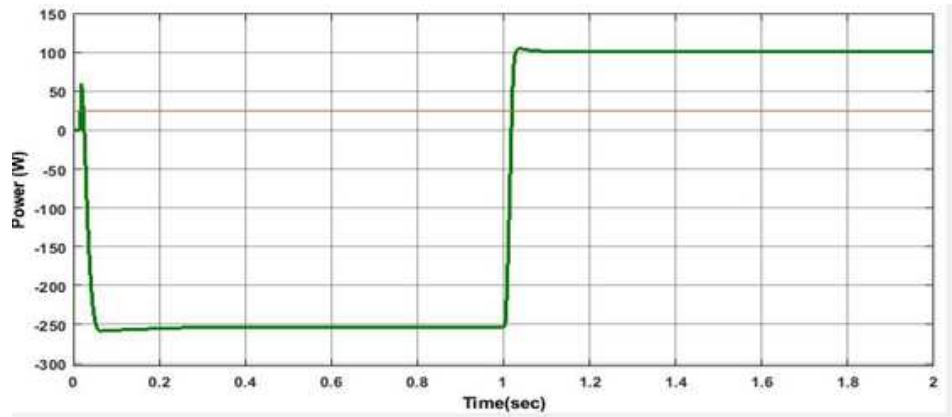

(d) Battery Power

Figure 5

Simulation results of frequency deviation, SOC, battery current and battery power. 


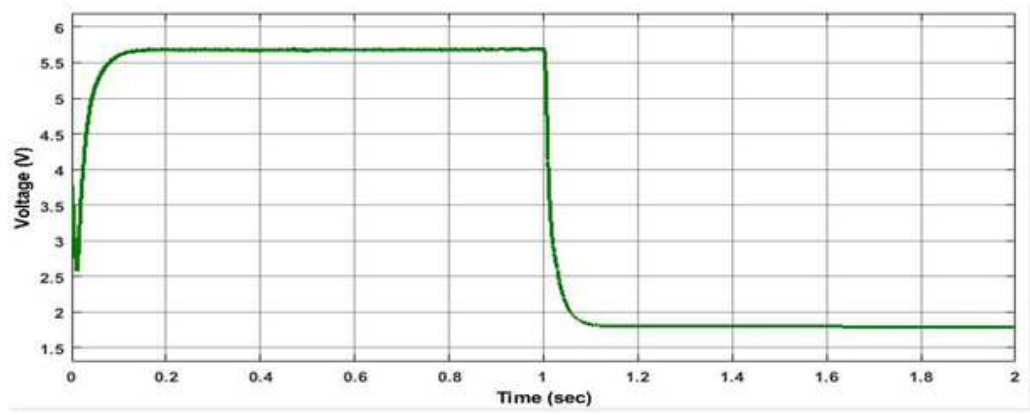

(a) Frequency Deviation

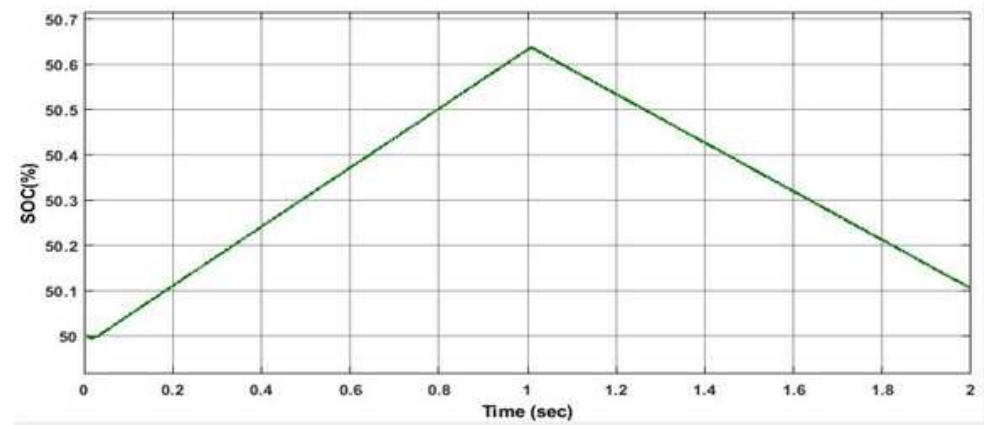

(b) $\%$ of SOC

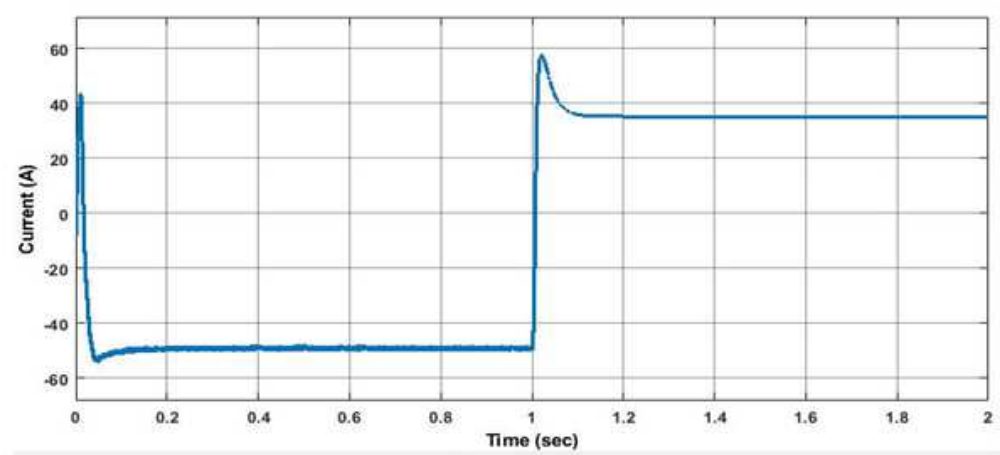

(c) Batterv Current

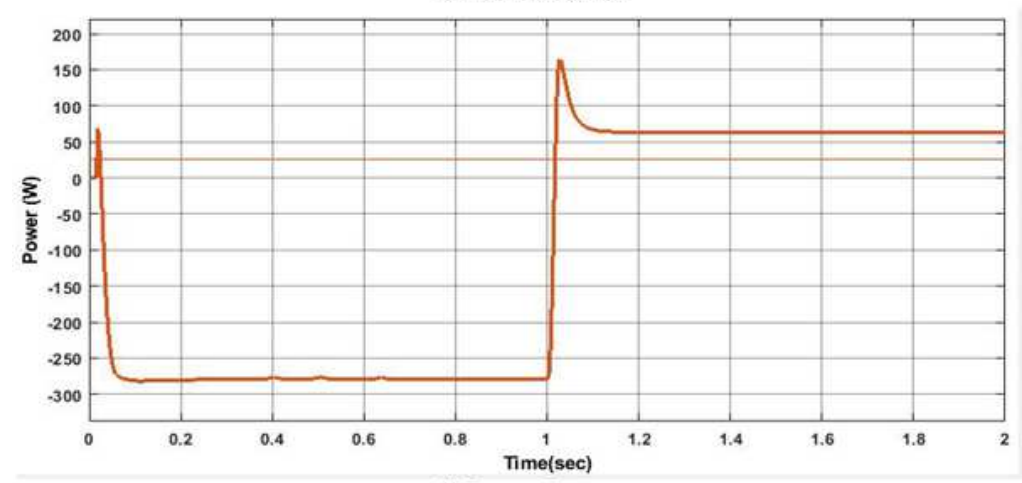

(d) Battery Power

Figure 6

Experimental results of frequency deviation, SOC, battery current, and battery power 


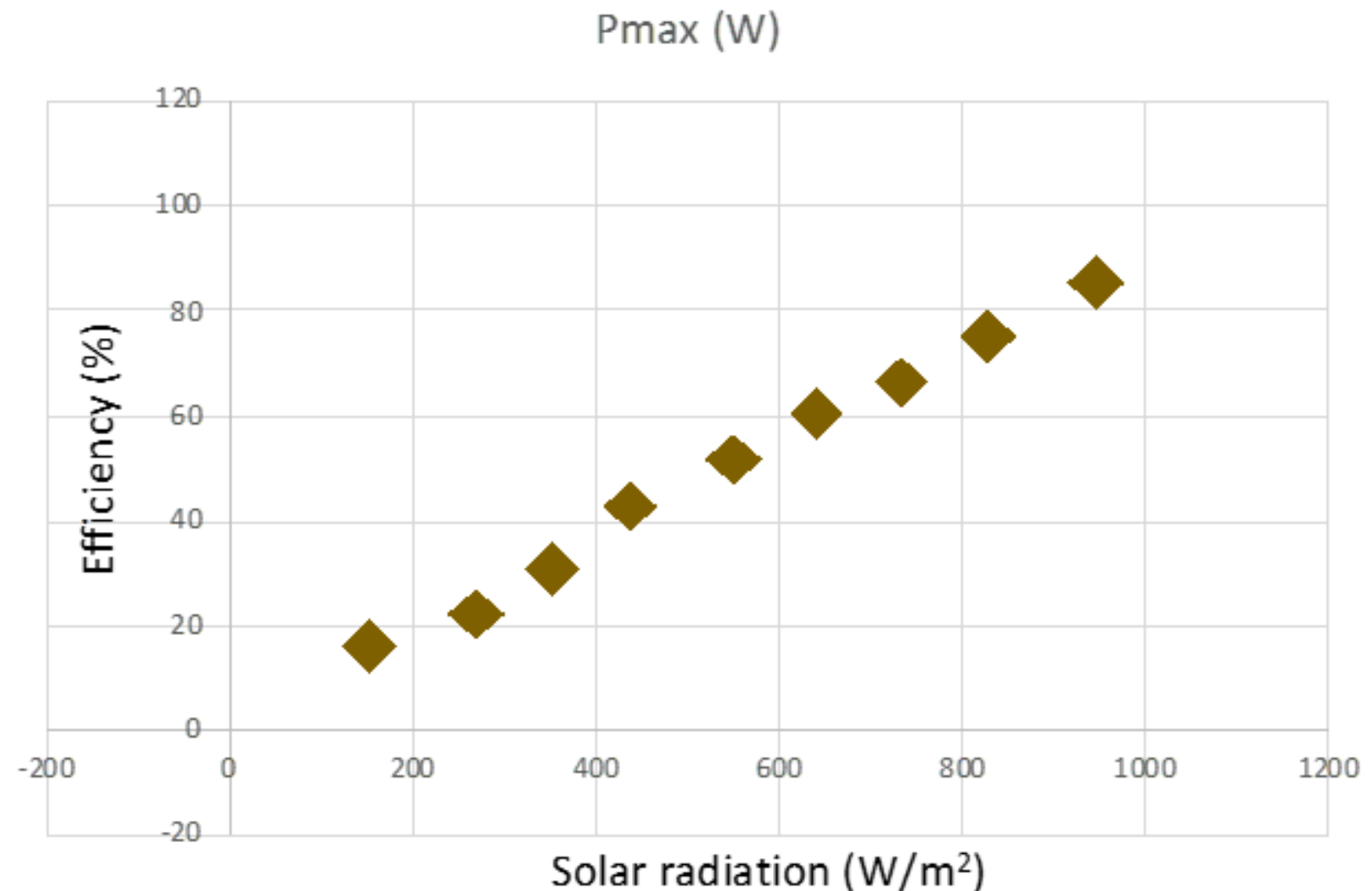

Figure 7

The efficiency and maximum power 